of that base. The picolines are even better solvents than pyridine, in some cases being equal to and even surpassing carbon disulphide.

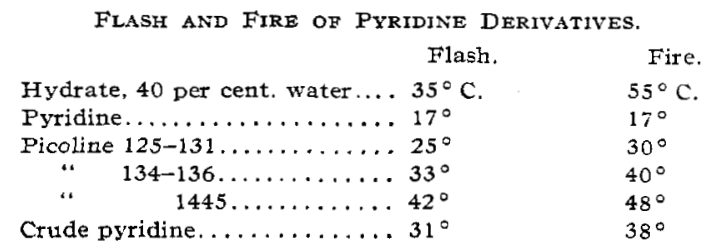

Apparatus $=4$ oz. open tin dish 2-I $/ 4^{\prime \prime}$ diameter.

NEW YORK TESTING LABORATORY,

MARCH 31, 1909.

\section{PURITY OF COMMERCIAL LIQUEFIED AM- MONIA GAS AND APPARATI FOR TESTING IT. ${ }^{1}$}

By Dr. F. W. FrERICHS.

The following paper discusses the purity of commercial liquefied ammonia and describes the principal apparati, which have been proposed for testing its purity in the United States and in Europe.

The test is based upon the low boiling point of liquefied ammonia gas, which is $28^{\circ} \mathrm{F}$. below zero, and upon the consideration that the impurities, which are likely to be present, have a much higher boiling point. Therefore if a sample of liquid ammonia be evaporated the impurities contained in same would probably remain in the vessel, and their quantity could be ascertained. Liquefied ammonia gas now is considered good by American

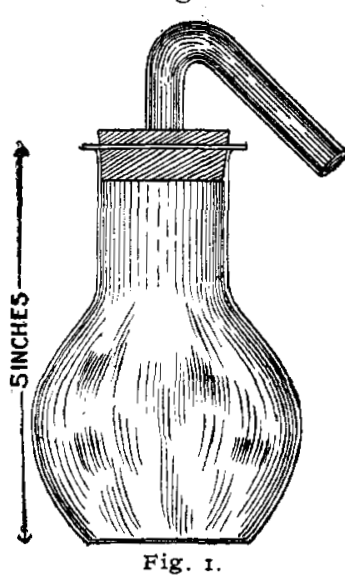
ice manufacturers if no visible residue is left in a flask in which a 4 oz. sample has been evaporated.

Fig. I shows a test bottle similar to the one in common use in the United States, and Fig. 2 shows the mode of drawing a sample from a cylinder of ammonia.

This mode of testing gives only approximate results. One source of error is the moisture contained in the surrounding atmosphere. On account of the rapid evaporation of the liquid ammonia, the iron tube by which the sample is drawn beconies very cold and so does the flask, and moisture from the air will readily condense upon the cold surfaces. By drawing the

1 This paper was read at the first annual meeting of the American Insatitute of Chemical Engineers and will be published in full in the Transactions, Vol. 1, 1908. sample quickly, and closing the flask at once with a perforated cork carrying a bent glass tube, contamination of the sample with moisture is as much as possible, but never entirely, prevented. But the fundamental source of error in this method of testing rests in the fact that small quantities of the

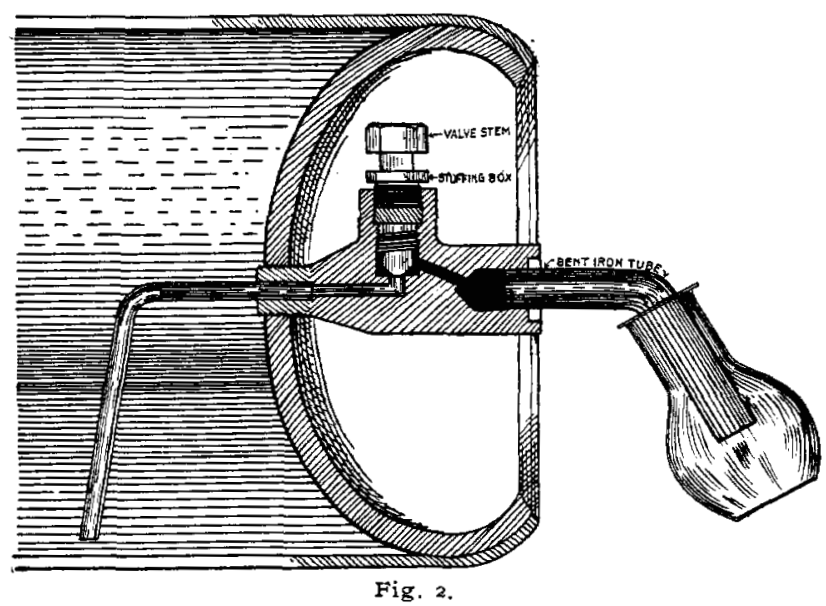

impurities often contained in the commercial ammonia will evaporate with the ammonia used for the sample, on account of which fact the evaporation test gives results, which are too low.

While this method of testing has become customary in the United States, the Linde method was used in Europe. The apparatus shown by Fig. 3 is used for the Linde test, and consists of a wider tube with a small hole near the center, the tube being drawn out at one end into a smaller tube which is closed in the bottom. The graduation was as indicated in the picture. In making the test the tube was supposed to be filled to the opening in the center, and the sample was permitted to evaporate in the open air. In operating this apparatus it would frequently occur that the ammonia would foam and boil up and part of the sample would run out of the opening. Since the time of $\mathbb{E}$ evaporation was directed to be about three hours, the open vessel would permit much moisture to be attracted from the air. Besides, the graduation was incorrect because it did not take into consideration the difference in the

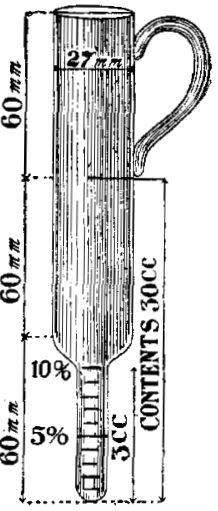
Fig. 3 . specific gravities of the liquid ammonia, and of the residue left upon evaporation. For these reasons the results could not be accurate, but the degree of purity expected by European ice makers was not very

${ }^{1}$ Zeitschrift f. angew. Chemie, 1897, p. 224. 
great, an article leaving, upon evaporation, I per cent. of liquid residue being quite acceptable to them. ${ }^{1}$

Lange and Hertz ${ }^{2}$ improved upon this apparatus and changed it to the form shown by Fig. 4. They omitted the overflow hole and replaced it by a mark indicating $49 \mathrm{cc} .=33.3$ grams ammonia.

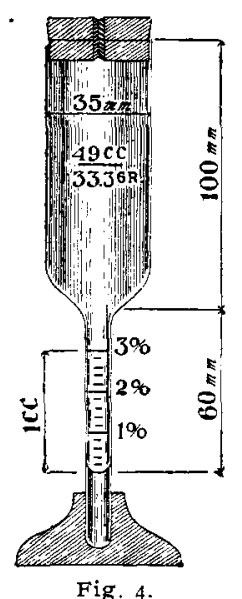

Fig. 4 . They increased the size of the sample from $30 \mathrm{cc}$. to $49 \mathrm{cc}$, and narrowed the tail end in order to permit a larger graduation. The latter they made proportionate to the specific gravities of the fluids to be measured. Finally they closed the tube with a cork during the time of evaporation, which was about three hours, letting the ammonia vapors escape through a narrow notch in the stopper. The result of tests made with this apparatus seemed to be sufficiently correct, since they worked with

liquefied ammonia gas, leaving, upon evaporation, about I per cent. of non-volatile liquid. They also reported upon the quality of several German makes, finding that the average commercial article left, upon evaporation, about I per cent. of an oily substance. The nature of this residue of which they secured $\mathrm{I} 85 \mathrm{cc}$. by evaporating $\mathrm{I} 9.5$ kilograms of commercial liquid ammonia was analyzed and ethyl alcohol, acetonitril, and pyridine were found in larger quantities, while the presence of smaller amounts of benzol, naphthalin, and carbonate of ammonium, and also lubricating oil could be established.

Since it was evident that both the Linde, and the Lange and Hertz test would show, upon evaporation, more residue than the ammonia really contained, the Aktiengesellschaft für Chemische Industrie in Mannheim caused Bunte and Eitner to design a new method which they published in $1897 .^{3}$ Their apparatus is repre-

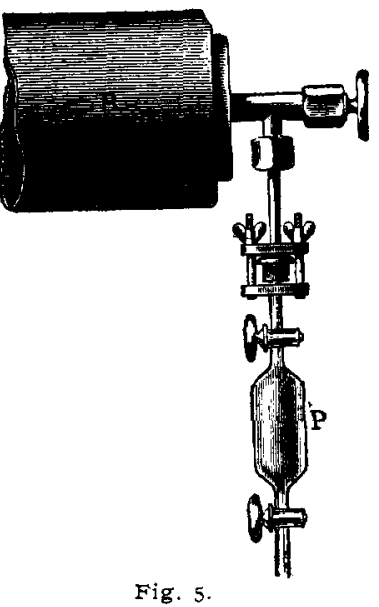

Fig. 5 .
The sample was drawn under pressure, and its weight was ascertained. The pipette was then put in an upright position, the upper end connected with three caustic potash drying tubes, and by opening the upper faucet the sample was permitted to evaporate. After evaporation the pipette containing the residue was heated in an air bath to $70^{\circ}-80^{\circ} \mathrm{C}$. subjected to a current of air at that temperature and the weight of the von-volatile liquor was ascertained.

It is evident that the method favored the seller, since it generally would show a good test, the current of air carrying most of the residue out of the apparatus.

$\mathrm{K}$. Urban ${ }^{1}$ has improved upon this method, using an apparatus represented by Fig. 6 . He graduated his pipette and heated the residue only to $30^{\circ} \mathrm{C}$. to expel ammonia, but he did not use a current of air nor did he use caustic potash tubes. The specific gravity of the residue he determined by reading the volume on the graduation and ascertaining the weight. But he made an error by not considering the difference of specific gravities of air and ammonia gas, which was for his apparatus about

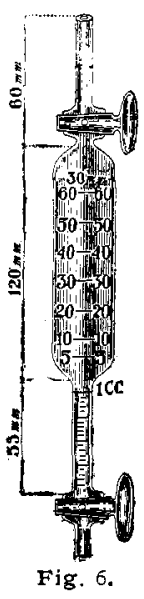
thirty milligrams. Urban compared his method with other methods of testing then in us, and tabulated his results as shown in Table I.

TABLE I.

A. By URBan's Method.

$43 \mathrm{cc} .=26.5$ grams $\mathrm{NH}_{3}$ left $0.25 \mathrm{gram}=0.94$ per cent. residue $43 \mathrm{cc} .=26.5$ grams $\mathrm{NH}_{3}$ left 0.25 gram $=0.94$ per cent. residue $45 \mathrm{cc}$. $=27.7$ grams $\mathrm{NH}_{3}$ left $0.25 \mathrm{gram}=0.91$ per cent. residue B. BY LINDE'S METHOD.

$30 \mathrm{cc} .=20.4$ grams $\mathrm{NH}_{3}$ left 0.534 gram $=2.61$ per cent. residue. $30 \mathrm{cc} .=20.4$ grams $\mathrm{NH}_{3}$ left 0.530 gram $=2.59$ per cent. residue. $30 \mathrm{cc}$. $=20.4$ grams $\mathrm{NH}_{3}$ left 0.535 gram $=2.62$ per cent. residue. C. By the Lange and Hertz Method,

50 cc. $=34$ grams $\mathrm{NH}_{3}$ left 0.45 gram $=1.32$ per cent. residue. $50 \mathrm{cc} .=34$ grams $\mathrm{NH}_{3}$ left 0.46 gram $=1.35$ per cent. residue. 50 cc. $=34$ grams $\mathrm{NH}_{3}$ left 0.45 gram $=1.32$ per cent. residue. $50 \mathrm{cc} .=34$ grams $\mathrm{NH}_{3}$ left 0.51 gram $=1.50$ per cent. residue. $50 \mathrm{cc} .=34$ grams $\mathrm{NH}_{3}$ left $0.50 \mathrm{gram}=1.47$ per cent. residue.

The last publication upon this subject has been by Lange and Heffter $1898^{2}$ who reject the Linde method as being incorrect, and prove that the Bunte Eitner method is unreliable since its results are always too low. Then they compare the Urban and the Lange-Hertz methods, and prove by a number of experiments on samples of liquid ammonia containing known quantities of benzol,

1 Chemiker $Z_{\text {to., } 1897, \text { p. } 720 .}$

2 Chemische Industrie, 1898, p. 2.
1 Lunge, "Coal, Tar and Ammonia," 4th German Edition, p. 161

2 Zeits. f. angew. Chemie, 1897, p. 224.

3 Journal fï̈r Gasbeleuchtung. 1897, p. 174. 
alcohol, pyridine, acetonitril, and also of mixtures of either two of these in equal parts, that Urban's method gives always too low results, while LangeHertz's method produces too high figures. In making the investigation they have operated with liquid ammonia leaving 0.2 per cent. residue upon evaporation, this being the best commercial ammonia which they could obtain. The results of their experiments are compiled in Table II.

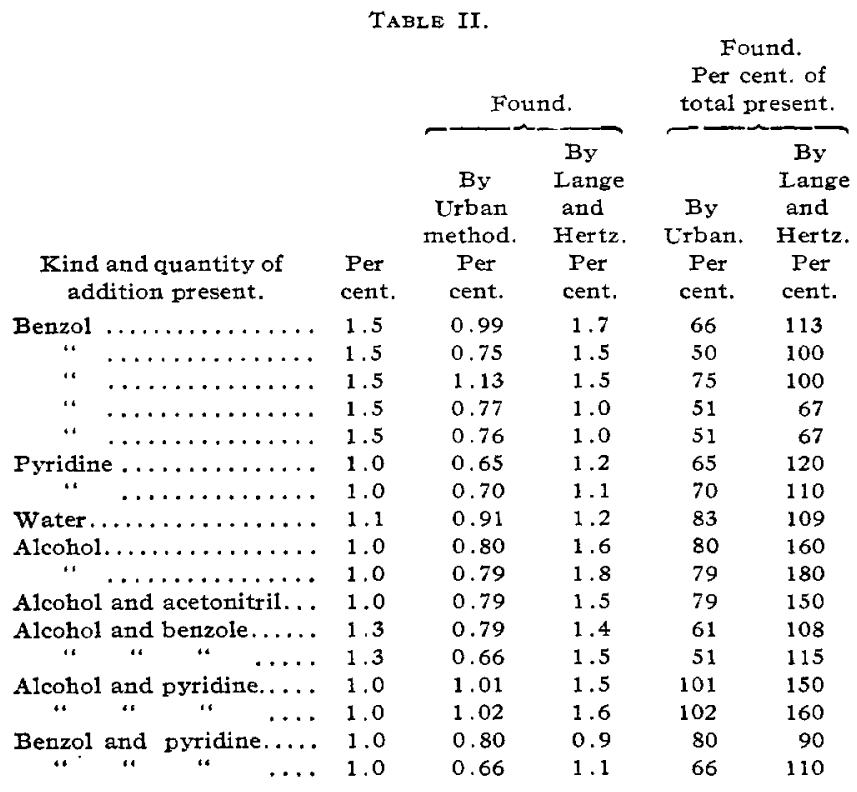

They conclude that in Urban's method part of the impurities evaporate with the ammonia, and prove this theory by leading the vapors of 20 grams ammonia through a tube filled with pumice stone and cooled to $-30^{\circ} \mathrm{C}$., whereby the tube increased in weight by 26 milligrams.

They found that the amount of foreign substances evaporated with the ammonia varied with the nature of the substances. Benzol and pyridine escaped easily, alcohol and water with greater difficulty. Of the mixtures, alcohol and pyridine in equal parts did not seem to evaporate with the ammonia. However, with this statement I cannot agree. I have repeated this series of tests and the results are compiled in Table III. My figures show that a mixture of pyridine and alcohol evaporates just as well with ammonia as other substances. As a result of their investigation Lange and Heffter conclude that the results obtained by Urban's method are always too low while those obtained by the method of Lange-Hertz are too high, and they suggest to make both tests and take the average. This would seem quite arbitrary, but Lange-Heffter do not consider it worth while to look for a better method as long as no purer ammonia is offered in the market than an article leaving upon evaporation 0.2 per cent. residue.

\begin{tabular}{|c|c|c|c|c|}
\hline \multirow{3}{*}{$\begin{array}{l}\text { Liquid } \\
\text { HNi. }_{3} \\
\text { Grams. }\end{array}$} & \multicolumn{2}{|c|}{ Addition present. } & \multicolumn{2}{|c|}{ Addition evaporated.] } \\
\hline & & & By Urban. & By Frerichs. \\
\hline & Kind. & Grams. & Per cent. & Per cent. \\
\hline 98.5 & Benzol & 1.5 & 41 & 59 \\
\hline 99.0 & Pyridine......... & 1.0 & 33 & 24 \\
\hline 99.0 & Alcohol......... & 1.0 & 20 & 17 \\
\hline 98.9 & Water........... & 1.1 & 17 & 11 \\
\hline 99.0 & $\left.\begin{array}{l}1 / 2 \text { Alcohol } \\
2 / 2 \text { Pyridine }\end{array}\right\} \ldots$ & 1.0 & 00 & 15 \\
\hline Used & $\begin{array}{l}\mathrm{NH}_{3} \text { leaving, upon } \\
\text { oration, }\end{array}$ & & 0.2 & 0.00 \\
\hline
\end{tabular}

This was the aspect of the situation in Europe in 1898 and it would seem that the conditions are still the same at the present day. ${ }^{2}$

In the United States, the refrigerating industry has made much quicker progress than abroad. In the same measure as the ice plants multiplied and ice-making machinery became more perfect, the importance of the purity of the ammonia used in the plants became more evident because impure ammonia produced permanent gases in ice machines, and thereby decreased the efficiency of the plants.

As early as 1892 , Hans von Strombeck, then in the employ of the De la Vergne Machine Company, published the analysis of six samples so called "anhydrous liquid ammonia roo per cent." manufactured of different materials by different processes. He evaporated the samples in a flask connected with a long upright spiral condenser cooled with a refrigerating mixture, and obtained residues corresponding to the figures given in Table IV. The

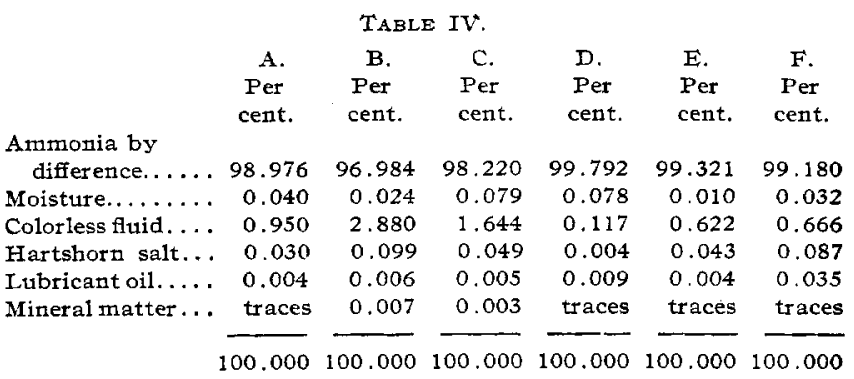

colorless fluid he obtained by distillation of the crude residue under the reduced pressure of 200 nm. mercury, when it distilled at $106^{\circ}-122^{\circ} \mathrm{F}$. By repeated fractional distillation he could separate it into fractions, the boiling points of which corresponded with methyl alcohol, acetone, ethyl

$1 \mathrm{By}$ an error in the first publication. This Journal, 1, 224, benzol has been printed instead of alcohol. Kindly correct.

"See H. Teichman's book on "Compressed Gases," p. 101, published 1908. 
alcohol, and isopropyl alcohol. Believing only alcohol and acetones present as contaminations of commercial liquid ammonia, v. Strombeck proposed to purify it by distilling over metallic sodium. This process has been patented, and it was claimed that liquid ammonia 99.995 per cent. purity could be obtained by it.

v. Strombeck evidently overlooked benzol and pyridine among the impurities, and for that reason could not have obtained as pure ammonia as he thought. I have not been able to find that this process has been carried out on a large scale, but his investigation served as an incentive for other manufacturers to improve their product, and to furnish to the ice trade an article of such purity as they do now.

In the winter of $1897-98$ the writer had to rebuild the ammonia works of the Herf \& Frerichs Chemical Company, and in order to control the working of the plant the larger of these two test apparati has been constructed. It aims to test the ammonia under such conditions as are prevailing in ice machines, inasmuch as the evaporation takes place under pressure, while the sample evaporated at a low temperature produced by a freezing mixture. The test apparatus was permanently connected with the plant, and a sample was taken from every $2 \mathrm{I} 2$ pounds ammonia manufactured. Apparati were changed and purifiers were added to the plant until the resulting ammonia upon evaporation in this apparatus did not leave any visible residue. In order to be still surer that the ammonia was pure an upright Liebig condenser cooled first by liquid ammonia, and subsequently by liquid carbonic acid, was connected with the flask containing the samples, and even in this case the evaporating ammonia did not leave any visible residue.

In one instance 235 consecutive samples, one from every $2 \mathrm{I} 2$ pounds of ammonia manufactured, representing altogether 49820 pounds of ammonia, were evaporated in the same flask leaving, upon evaporation, only 0.0187 gram of a residue containing moisture, iron rust, traces of ammonium carbonate, and a little lubricating oil.

The apparatus is illustrated by Figs. 7 and 8 , and Fig. 9 shows the same apparatus without the Liebig condenser attached to a shipping cylinder containing liquefied ammonia gas.

"A" represents a cylinder containing liquid anhydrous ammonia. The test apparatus is attached to the valve " $B$," as indicated in the cut.
Channel 4 terminates in the cross-channel 5 , in the ends of which the valves 6 and 7 are located. By opening valves " $B$ " and 6 , connection with the outer air can be made through the opening 8 , whereby any rust, etc., from the valve can be

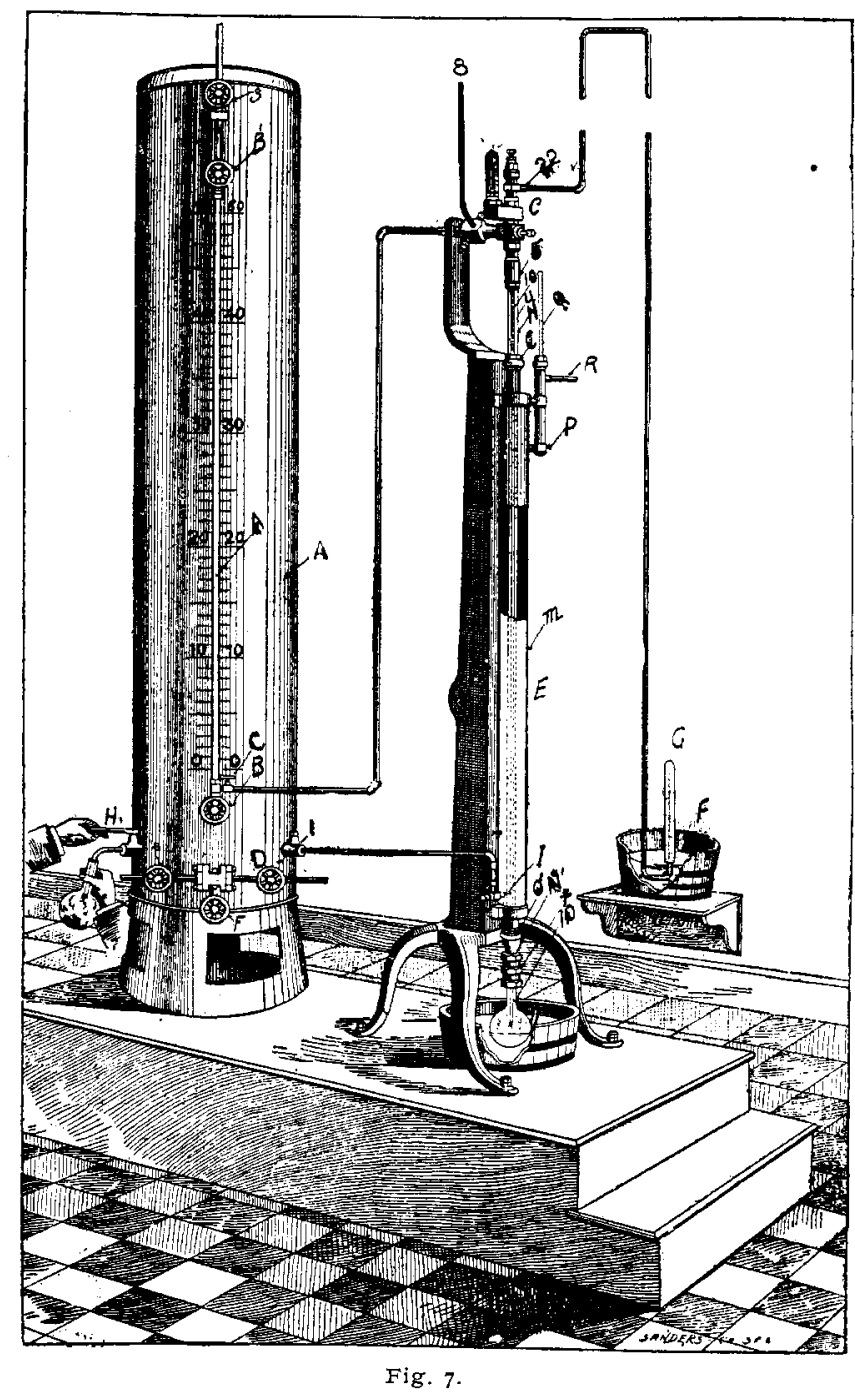

blown off. By valve 7 , connection can be established between channels 4 and 9, the latter extending by means of the tube ro to the center of the flask II, which is strong enough to withstand a pressure of 30 pounds, to the square inch.

The interior of the flask connects by way of channels $15,16,17$, I 8 with the automatic valve I9, and the spring 20 (the pressure of which can be regulated by the screw $2 \mathrm{I}$ ) holds the valve I 9 in its seat, allowing only gases to escape through channel 22 if their tension is great enough to overcome the pressure of the spring. Valve 23 controls connection with the mercury gauge 24 , which 
indicates the pressure under which evaporation takes place.

In operating the apparatus it is attached to the cylinder of anımonia to be tested as indicated by the cut, and valve " $B$ " is opened, all other valves of the apparatus being closed. By opening valve 6 , some ammonia is blown off in order to remove

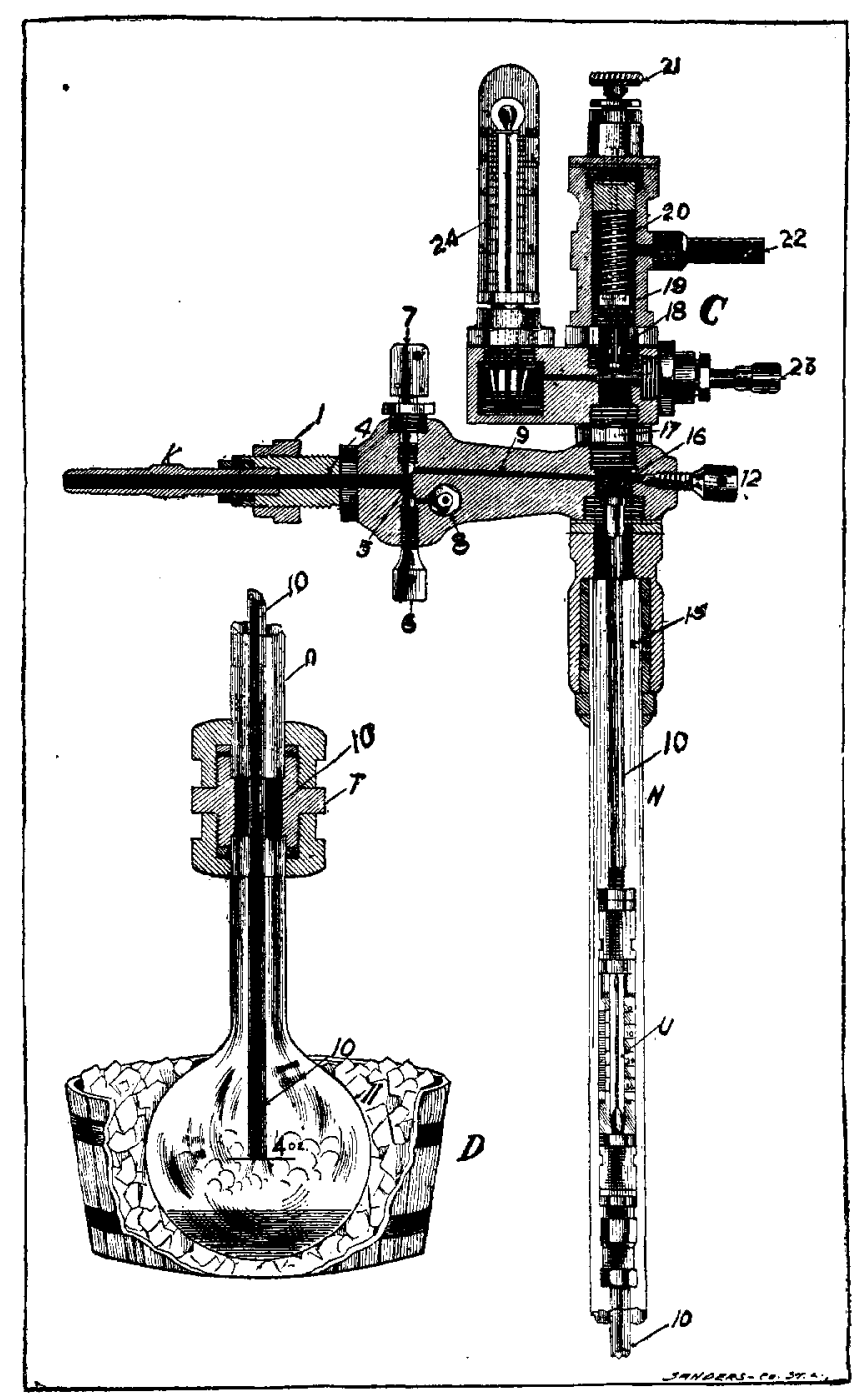

Fig. 8 .

the rust or other foreign matter which may have gathered in valve $B$. If this has been accomplished, valve 6 is closed while valve 23 is opened and by operating valve 7 , such quantities of ammonia are admitted into flask II as may be found convenient for the test.

The evaporation of the ammonia in flask II begins at once, and by means of the screw 2 I the pressure under which the evaporation is to take place can be regulated to the desired degree, which is indicated by the mercury gauge 24 . The evaporated ammonia escapes at 22 .

If all the ammonia which has been admitted for a sample into flask I $\mathrm{I}$ has been evaporated, a new sample can be filled into the same flask by operating valve 7 , the apparatus being in the same condition in which it was at the beginning of the test, except that flask II now contains whatever impurities may have been left from the evaporation of the first sample. In this way a great many tests may be made in succession, and the entire contents of the cylinder can be evaporated in the small flask I i in which remain, at the end of these tests, all the non-volatile impurities which have been contained in a very large amount of ammonia.

The smaller of these apparati has been constructed in more recent time; its particular object is to make the test independent from the moisture of the atmosphere. It is illustrated by Figs. Io and I $\mathrm{I}$, which explain themselves.

The apparatus is attached to the vessel containing the ammonia as shown in Fig. Io, and all rubber tubing is secirrely fastened with copper wire, wherever such joints occur. Ready for use the main valve on the ammonia cylinder is opened, and by opening the thumbscrew I some ammonia is blown off in order to remove rust and dirt which may have accumulated in the valve; this also will remove the small quantity of oil, which may have been used for lubricating the screw on the valve stem and which is always likely to be present in the interior of the valve.

If sufficient ammonia has been blown off to clear the valve, thumbscrew $I$ is shut, and by opening thumbscrew 2 a sample of ammonia is admitted to the test bottle.

Care must be taken that ammonia is not admitted too quickly, otherwise the pressure in the bottle will become too great and either the bottle or the rubber connections are liable to burst. A Bunsen valve permits the ammonia vapor to escape, but prevents moisture of the air from entering the bottle.

The sample is permitted to evaporate while the apparatus remains attached to the cylinder. Evaporation may be hastened by dipping the graduated tail of the test bottle in cold water, whereby a gentle and steady boiling of the ammonia is kept up. Care should be taken not to dip the test bottle too deep into water, otherwise the ammonia may boil too rapidly and the bottle may explode 
by excessive pressure. The slower the sample is evaporated the more reliable is the test. One hour and a half is a good time for evaporating roo cc. ammonia in this apparatus. If evaporation is effected in much less time, the rapidly boiling ammonia will take with it some of the impurities, particularly hydrocarbons, if such are present and an inferior ammonia may show a good test.

During the evaporation, the tail of the test bottle will be heavily coated with ice, which will readily off after the sample of ammonia has evaporalud by gently agitating the water in the surrounding vessel.

If Ioo cc. are taken for the test, and if there remains some liquid in the tail of the test bottle, each subdivision in the scale indicates $\mathrm{I} / \mathrm{I}$ o of $\mathrm{I}$ per cent. by volume in the ammonia.

A second and third sample can be evaporated in the same bottle without removing the apparatus from the cylinder and this may be continued until the entire contents of a cylinder has been evaporated, in which case the test bottle will contain all of the impurities which have been contained in the entire cylinder.

Before taking a new test some ammonia is blown off by opening thumbscrew $I$ in order to remove as much as possible the traces of oil which may have seeped into the valve from the lubricant used for the valve stem.

If more accurate results are desired the Bunsen valve on the side outlet of the flask is replaced by a bent glass tube leading the ammonia gas into water where it is absorbed. A Bunsen valve attached to the end of the glass tube, which dips into the water, prevents the water from backing up into the test flask. The amount of the ammonia used for the test is then ascertained by titrating the solution of ammonia in water, and the amount of residue left upon evaporation is determined by weighing the test flask before and after the test on a chemical balance. Care must be taken to close the outlets of the flask, and to have constant temperatures while weighing, also to have the flask entirely filled with anımonia gas in order to exclude errors resulting from the difference in the specific gravities of air and ammonia gas.

Liquefied ammonia gas seems to be an absorbent for permanent gases. They may be determined with the aid of this apparatus by collecting them in a eudiometer filled with water after the ammonia gas has been absorbed in the water of a pneumatic trough. If this be done care should be taken to use

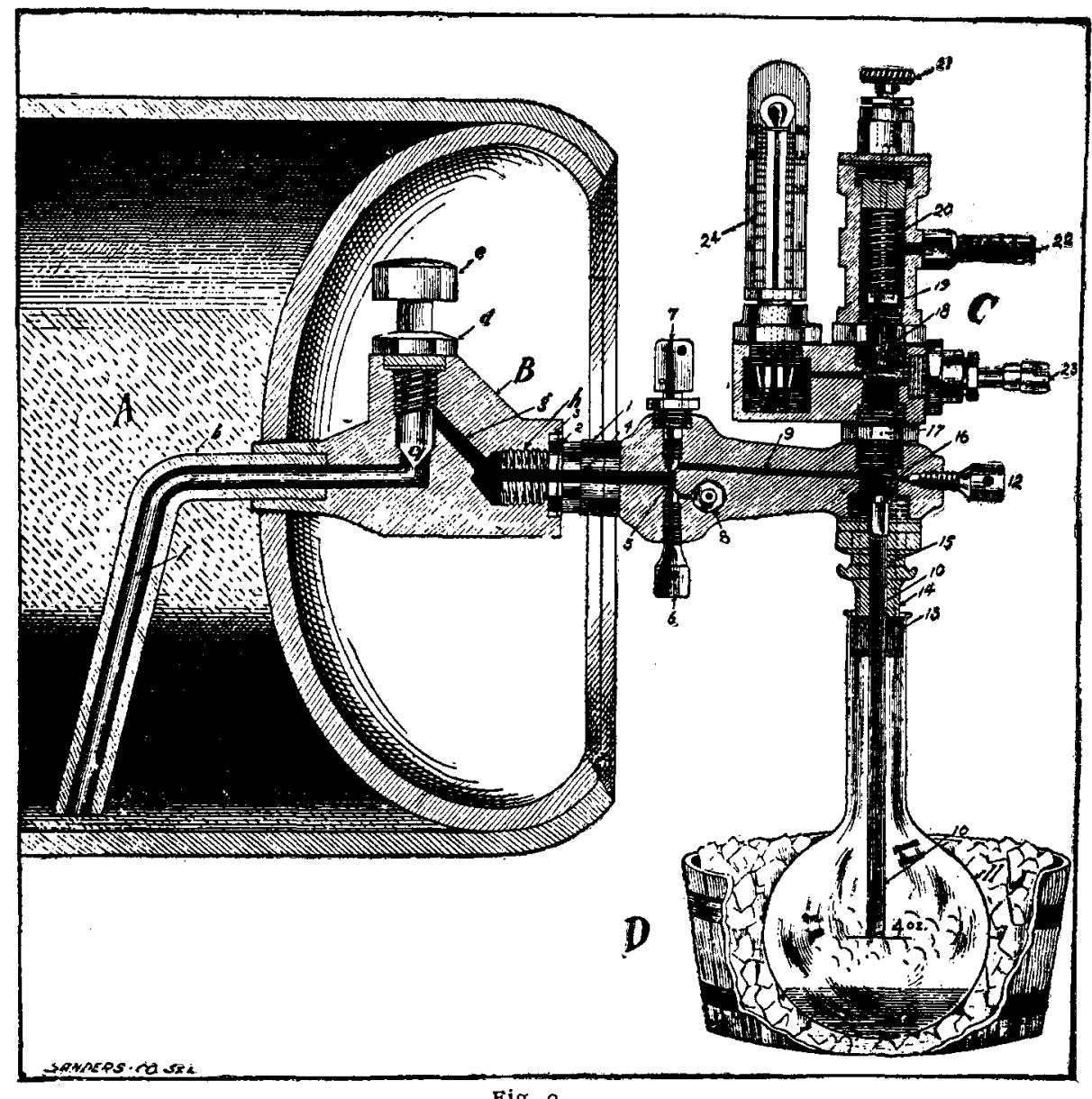

Fig. 9.

water which has been freed from air by protracted boiling since anmonia gas disengages air from water which is saturated with it.

Small quantities of alcohols and water can be determined in liquid ammonia by treating it with metallic sodium and measuring the quantity of hydrogen evolved. The mode of operation is as follows:

Sufficient sodium is inserted into the test flask, which is then connected with the test valve and provided with the extension tube and eudiometer 
filled with water and standing in a pneumatic trough. Some liquid ammonia is admitted which dissolves the sodium to a dark blue liquid, the evaporating ammonia expelling the air from the

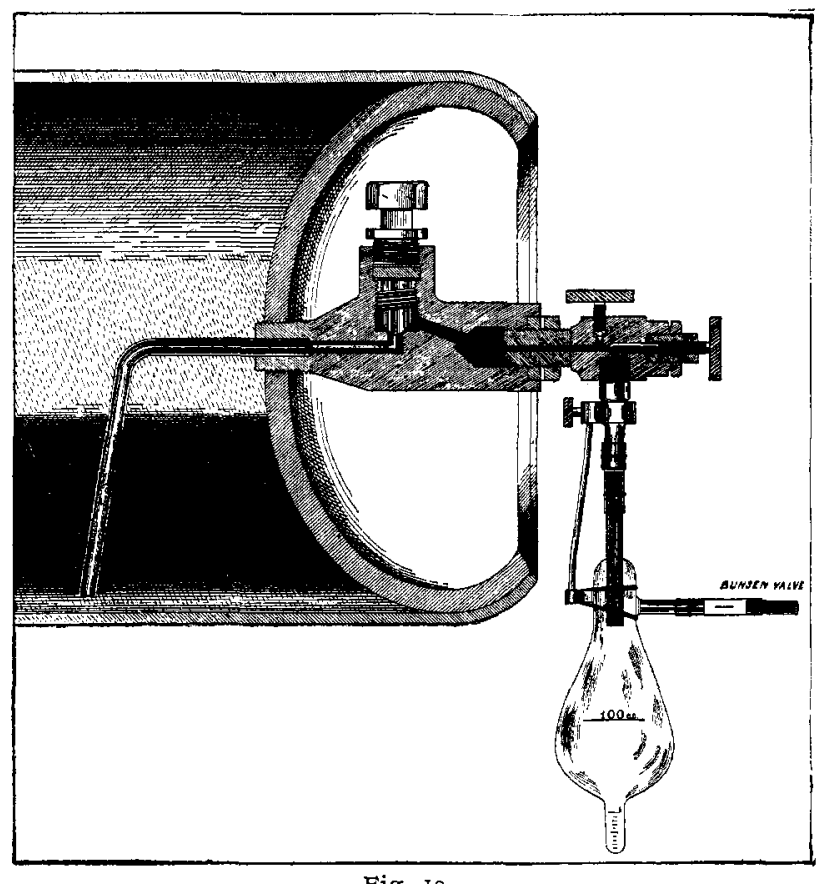

Fig. 10.

flask. If the ammonia has evaporated to I cc., and if the air has been expelled the glass tube is inserted into the pneumatic trough and under the opening of the eudiometer and ammonia for the sample is admitted. Hydrogen is evolved at once as a result of the decomposition of water and alcohols contained in the ammonia. If the sample has evaporated to I cc. the volume of hydrogen is measured and the amount of ammonia absorbed in the water of the pneumatic trough is determined by titrating, giving the data for calculation. The results obtained by this method are a little too high because anmonia is decomposed slowly by sodium to sodium amide and hydrogen. But it would seem that this secondary reaction is so slow that the result is only slightly affected.

With this apparatus, a series of tests has been made with a view of ascertaining its accuracy in determining the various impurities, which are most frequently contained in commercial liquefied ammonia gas.

As a basis, liquid ammonia was used which had been manufactured in the regular run of the works from sulphate of ammonia previously purified from all volatile carbon compounds, and in the manufacture of the product great care was taken that all the moisture was eliminated. For this reason it was certain that bodies like benzol, pyridine, alcohols, and other carbon compounds could not be present, and the limit of water was ascertained by analysis to be less than 2 milligrams in 100 grams of liquid ammonia. The determination of water was made by adding an ammoniacal solution of metallic sodium to the liquid ammonia to be analyzed, and collecting the hydrogen, which was evolved by reaction of the sodium upon the water in the sa, sle. Ioo grams of the liquid ammonia treated in this way produced $2.4 \mathrm{cc}$. hydrogen. If all the hydrogen had been produced from water 2 milligrams of water must have been present, but it is well known that ammonia itself decomposes slowly with sodium into sodium amide and hydrogen and for this reason part of the hydrogen may have come from the ammonia, in which case the water present would be less than 0.002 per cent. As a fact, I will state that about one-half of the hydrogen was developed rapidly right after the sodium solution had been added, while the balance accumulated from minute bubbles during the time of evaporation of the entire hundred grams of the liquid ammonia, and for this reason it is quite possible that the second half comes from decomposition of ammonia. Therefore, under no circumstances could more than 0.002 per cent. water

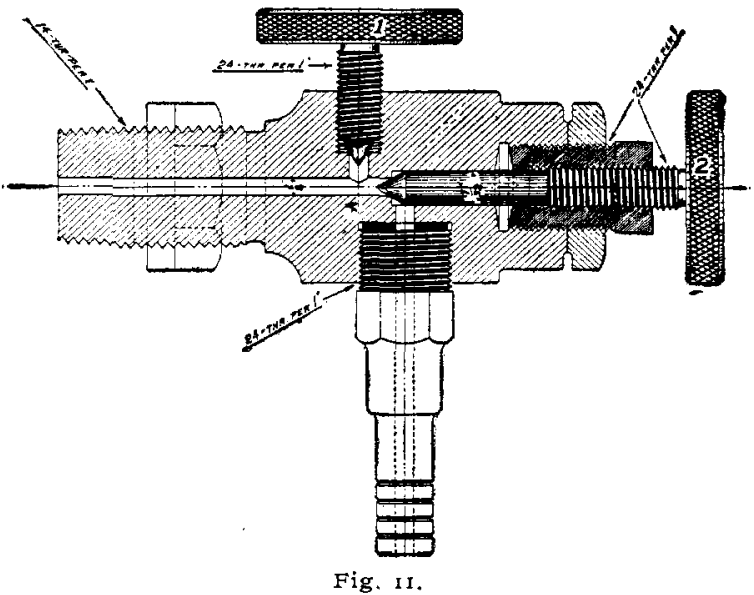

be present, and it is possible that the quantity of water in the sample was not more than half of that amount. Table $\mathrm{V}$ gives the result of five tests made with this ammonia in the smaller of the two apparati and from the uniformity of the results and the insignificance of the residue the purity of the liquid ammonia is evident. 
TABLE V.

80 grams liquid $\mathrm{NH}_{3}$ left after evaporation $0.003 \mathrm{gram}$. 160 grams liquid NHr ieft after evaporation $0.003 \mathrm{gram}$. 240 grams liquid $\mathrm{NH}_{3}$ left after evaporation $0.003 \mathrm{gram}$. 320 grams liquid $\mathrm{NH}_{3}$ left after evaporation $0.005 \mathrm{gram}$. 400 grams liquid $\mathrm{NH}_{3}$ left after evaporation $0.007 \mathrm{gram}$. Residue from evaporation 0.00175 per cent.

Ammonia by difference 99.99825 per cent.

The residue consisted of iron oxide shown by potassium ferrocyanide, and little lubricating oil.

With ammonia of this purity, the experiments of Lange and Heffter have been repeated. The results $I$ have given in Table III. In addition a series of samples containing variable, but known quantities of benzol, pyridine, alcohol, and water have been evaporated in the new apparatus, and the residues left after evaporation have been ascertained as given in Table VI.

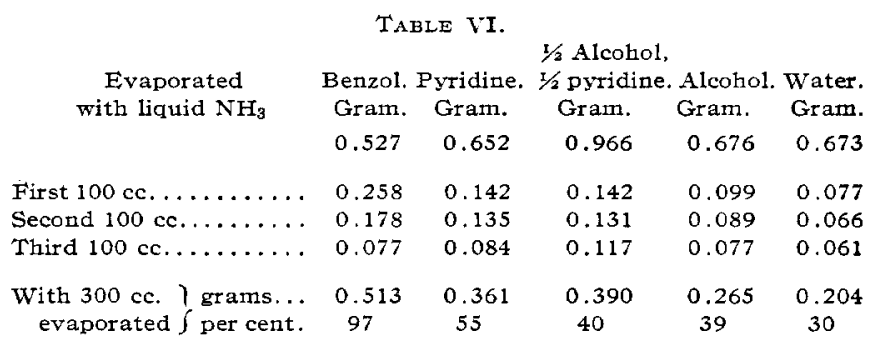

From this table it is evident that the quantities of the additions which evaporate with the ammonia decrease if less of the addition is present.

Table VII shows the same results differently

\begin{tabular}{|c|c|c|c|c|c|c|c|}
\hline & & & $T A$ & LE VII. & & & \\
\hline Ben & & Pyrid & dine & Alcol & hol & Wat & \\
\hline $\begin{array}{l}\text { present. } \\
\text { per } \\
\text { cent. of } \\
\text { ammo- } \\
\text { nia. }\end{array}$ & $\begin{array}{c}\text { evap., } \\
\text { pet } \\
\text { cent of } \\
\text { ben- } \\
\text { zol. }\end{array}$ & $\begin{array}{l}\text { present, } \\
\text { per } \\
\text { cent. of } \\
\text { ammo- } \\
\text { nia. }\end{array}$ & $\begin{array}{l}\text { evap., } \\
\text { per } \\
\text { cent. } \\
\text { of } \\
\text { pyridine. }\end{array}$ & $\begin{array}{l}\text { present, } \\
\text { per } \\
\text { cent. of } \\
\text { ammo- } \\
\text { nia. }\end{array}$ & $\begin{array}{l}\text { evap., } \\
\text { per } \\
\text { cent. } \\
\text { of } \\
\text { alcohol. }\end{array}$ & $\begin{array}{c}\text { present, } \\
\text { per } \\
\text { cent. of } \\
\text { amme- } \\
\text { nia. }\end{array}$ & $\begin{array}{c}\text { evap., } \\
\text { per } \\
\text { cent. } \\
\text { of } \\
\text { water }\end{array}$ \\
\hline 1.50 & 59 & 1.00 & 24 & 1.00 & 17 & 1.10 & 11 \\
\hline 0.65 & 49 & 0.81 & 22 & 0.84 & 14 & 0.84 & 11 \\
\hline .34 & 66 & 0.64 & 26 & 0.72 & 15 & 0.75 & 11 \\
\hline 0.11 & 84 & 0.47 & 22 & 0.61 & 16 & 0.66 & 11 \\
\hline
\end{tabular}

arranged. It gives the proportion of the addition evaporated with the ammonia to the total amount of the addition present before the evaporation, and a marked difference is observed between benzol on the one side and pyridine, alcohol, and water on the other. While the percentage evaporated seems to be the same for varying quantities of the addition present in the case of pyridine, alcohol and water, it increases rapidly with a decreasing addition of benzol.

The limit of accuracy of this mode of testing has been ascertained in a special series of experiments as follows:

\footnotetext{
For water to 0.002 gram in 100 grams ammonia. For alcohol to 0.006 gram in 100 grams ammonia. For pyridine to 0.009 gram in 100 grams ammonia. For benzol to 0.110 gram in 100 grams ammonia.
}

In other words, Ioo $\mathrm{cc}$. samples of liquid ammonia containing these additions, leave, upon evaporation, a visible residue of at least one milligram.

Herf and Frerichs Chemical Co., ST. LOUIS, Mo.

\section{NOTES AND CORRESPONDENCE.}

\section{RECENT LEGISLATION RELATIVE TO EXPLOSIVES IN THE MAIL AND TRANSPORTATION.}

The act to codify, revise, and amend the penal laws of the United States published as (Public-No. 350) and (S. 2982), approved March it, Igog and taking effect January I, IgIo, provides under offenses against the Postal Service.

Sec. 217 . All kinds of poison, and all articles and compositions containing poison, and all poisonous animals, insects, and reptiles, and explosives of all kinds, and inflammable materials, and infernal machines, and mechanical, chemical, or other devices or compositions which may ignite or explode, and all disease germs or scabs, and all other natural or artificial articles, compositions, or materials of whatever kind which may kill, or in any wise hurt, harm, or injure another, or damage, deface, or otherwise injure the mails or other property, whether sealed as first-class matter or not, are hereby declared to be nonmailable matter, and shall not be conveyed in the mails or delivered from any postoffice or station thereof, nor by any letter carrier; but the Postmaster-General may permit the transmission in the mails, under such rules and regulations as he shall prescribe as to the preparation and packing, of any articles hereinbefore described which are not outwardly or of their own force dangerous or injurious to life, health, or property: Provided, That all spirituous, vinous, malted, fermented, or other intoxicating liquors of any kind, are hereby declared to be nonmailable and shall not be deposited in or carried through the mails. Whoever shall knowingly deposit or cause to be deposited for mailing or delivering, or shall knowingly cause to be delivered by mail according to the direction thereon, or at any place at which it is directed to be delivered by the person to whom it is addressed, anything declared by this section to be nonmailable, unless in accordance with the rules and regulations hereby authorized to be prescribed by the Postmaster-General, shall be fined not more than one thousand dollars, or imprisoned not more than two years, or both; and whoever shall knowingly deposit or cause to be deposited for mailing or delivery, or shall knowingly cause to be delivered by mail according to the direction thereon, or at any place to which it is directed to be delivered by the person to whom it is addressed, anything declared by this section to be nonmailable, whether transmitted in accordance with the rules and regulations authorized to be prescribed by the Postmaster-General or not, with the design, intent, or purpose to kill, or in anywise hurt, harm, or injure another, or damage, deface, or otherwise injure the mails or other property, shall be fined not more than five thousand dollars, or imprisoned not more than ten years or both

It provides under the offenses against Foreign and Interstate Commerce. 